\title{
The Identification and Prevention of the Risk from EPC Project Owner
}

\author{
Hui Gao, Xiuhao Ding \\ School of Management, Huazhong University of Science and Technology, Wuhan 430074, China
}

\section{EPC 项目来自甲方风险的分析与管理}

高慧 丁秀好

华中科技大学管理学院, 武汉 430074, 中国

\begin{abstract}
As EPC mode is widely used in the large engineering projects and the engineering general contracting market competition is increasingly fierce, contract with own capital and party a-supplied materials has become the important characteristic of EPC project. From the perspective of general contractor, the risks from the owner gradually become the most challenging issue of many risk factors in the process of project construction. Based on project management theory and risk management process, this research aims to identify and measure the risk factors from the owner, and put forward countermeasures to provide scientific risk management basis for EPC project.
\end{abstract}

Keywords: General contractor, EPC project, Risk from owner, Risk management

\section{摘要}

随着 $\mathrm{EPC}$ 模式在大型工程项目中的广泛应用, 工程总承包市场竞争日趋激烈, 带资承包、甲 供物资等成为 EPC 项目的重要特征。对于总承 包商而言, 项目建设过程中风险因素众多, 来 自甲方的风险愈加成为现实中总承包企业面 临的严峻问题。本文依据项目管理理论及风险 管理过程, 基于总承包商视角识别项目建设过 程中来自业主方的风险因素, 并在此基础上提 出风险应对措施, 以期为 $\mathrm{EPC}$ 项目建设过程中 面临的甲方风险提供科学的风险管理依据。
关键词: 总承包商; $\mathrm{EPC}$ 项目; 来自甲方风险; 风险管理

\section{1. 引言}

Engineering-Procurement-Construction （EPC）工程总承包模式以其能够缩短周期、 降低成本、保证质量、提高效率的优势, 近年 来逐渐发展成为项目管理的主流承包模式, 广 泛应用于国内外大型综合工程项目的建设中。 $\mathrm{EPC}$ 项目投资金额大、建设周期长、不确定性 因素多、投资回收期长的特点, 以及 FIDIC 银 皮书关于风险分担的原则, 使得总承包商在项 目建设过程中承担绝大部分风险, 这对总承包 企业的风险管理水平提出了较高要求 ${ }^{[1]}$ 。

风险管理在很大程度上决定了项目的成 败, 工程建设的主体是项目的关键。现有关于 项目风险管理的研究大多集中在项目风险评 估方法的选择, 不同模式下项目风险管理, 项 目风险管理理论构建及研究方法等方面 ${ }^{[2]}$, 对 于 EPC 模式下的项目风险管理的研究较少, 且多以传统的工程风险因素分类方法进行风 险因素的分类 ${ }^{[3], E P C}$ 模式下基于总承包商视 角对源自业主的风险进行的研究则更为罕见。

在 EPC 项目的建设施工过程中, 总承包 会面临着宏观、中观和微观层面的各种风险因 素, 通常认为业主方 (也称“甲方”) 是项目投 资者, 不会成为项目风险因素的重要来源, 但 事实并非如此, 实务中 EPC 项目的总承包商 面临的重大风险之一便是来自甲方的风险。因 此, 基于总承包商视角对 EPC 项目源自甲方 的风险进行研究, 分析识别风险因素并提出风 


\section{Risk Analysis and Crisis Response in Big Data Era (RAC-16)}

险应对措施，具有重要理论与实践意义。

\section{EPC 模式下来自甲方风险的识别}

建筑业是构成国内生产总值和投资的主 要产业 ${ }^{[4]}$, 随着总承包市场竞争的日益激烈以 及总承包方式的急剧变革, 总承包企业为抢占
市场不得不接受甲方另一个可能亏损的项目 或者 “甲供材料” 的条件, 或者以 “带资承包” 的方式促使投标成功。采用 EPC 模式的工程 项目一般包括设计投标、采购、施工和试运行 四个阶段, 在项目全生命周期内, 总承包商面 临的来自甲方的风险如表 1 所示。

表1 EPC项目来自甲方的风险因素

\begin{tabular}{cccc}
\hline 项目阶段 & 风险种类 & 风险因素 & 影响结果 \\
\hline 投标设计 & 带资承包风险 & 融资风险、法律风险 & 财务危机、项目失败 \\
\hline 采购 & 甲供物资风险 & 道德风险、税务风险 & 增加成本、影响质量 \\
\hline 施工 & 甲方变更风险 & 需求变更风险、合同风险 & 索赔纠纷、延误工期 \\
\hline 试运行 & 交验风险 & 运维风险、技术风险 & 造成安全事故 \\
\hline
\end{tabular}

2.1 带资承包风险

在项目投标阶段, 总承包企业通常选择带 资承包的方式增强其在投标中的竞争力, “带 资承包” 的实质是一种工程承包的特殊融资方 式, 总承包商需以自有资金或融资资金帮助业 主解决资金问题，从而取得项目投标成功, 是 影响总承包商市场规模和市场份额的重要因 素。EPC 模式多应用于石油化工、电力、基础 设施等大型工程项目中，具有投资规模大、投 资回收期长、投资收益不确定性高的特点, 带 资承包对总承包企业的资金实力、融资能力及 抗风险能力提出了较高的要求。

带资承包风险主要源自于融资风险, EPC 项目的主要融资渠道包括银行贷款、信托贷 款、证券市场融资、企业联合承包融资四种, 尽管有多种融资渠道, 但在项目融资过程中仍 存在融资难度大、融资能力不足、成本高、效 率低、风险大等问题。项目建设期需投入大量 资金，随着投入金额的不断增加，融资风险也 随之增加, 若总承包企业的融资及再融资能力 不足、资金链断裂, 则会影响项目工期和工程 质量, 使得工期延后、预期成本超支。

带资承包的另一风险源于法律风险, 这一 行为的合法性存在极大争议, 并形成了截然对 立的两种观点 ${ }^{[5]}$ 。由于其非法融资的特征和本 质, 带资承包被认定为是违法行为, 且政府部 门通过颁布《关于严格禁止在工程建设中带资 承包的通知》明令禁止工程项目投标建设过程 中的带资承包行为 ${ }^{[6]}$; 《合同法》则对带资承 包持积极态度, 不轻易否定合同效力, 尊重契 约自由, 认为带资承包具有合法性。

\section{2 甲供物资风险}

采购阶段是指总包合同签订后, 总承包商 对项目所需物资设备的采购、运输、存储、使 用等进行计划、组织和控制的过程, 通常由总 承包商进行招标, 从多方竞价的供应商中选择 质量、价格最合适的一方或多方作为合作方提 供工程物资。为成功取得投标, 总承包商有时 需接受 “甲供物资” 的条件, 顾名思义即在签 订总承包合同时, 规定主要施工材料及设备由 业主方采购提供或指定供应商及品牌由总包 方购买, 验收后用于工程项目建设。工程物资 是构成项目建筑实体的重要因素, 其质量、数 量、成本、库存、管理等风险对项目质量及工 期有较大影响。

$\mathrm{EPC}$ 模式的优势在于总承包商可以整合 资源, 将设计、采购和施工阶段交叉融合, 统 筹协调配合缩短项目工期、节约建设成本, 为 优化管理、提升利润空间提供动力。 EPC 项目 合同签订后总承包商需承担绝大部分风险, 在 “甲供物资” 的条件下, 这些风险会放大, 虽 然总承包商无需进行物资采购, 但却因甲方参 与增加了这一环节的不确定性。首先是道德风 险, 由于在信息不对称的情况下存在项目采购 招标暗箱操作的可能性, 对工程质量、进度、 成本产生影响; 其次是税务风险, 包括税务监 管问责风险、稽查引发的税务风险及代扣代缴 风险等。

\section{3 甲方变更风险}

总承包合同规定, 变更是经业主指示或批 准的工程变更, 由业主方引起的工程变更有明 确变更和隐含变更之分, 主要包括功能描述书 
差错及遗漏、工作范围变更、计划需求变更、 设计变更、赶工期、工程暂停、合同终止等。 在项目全寿命周期内，假设甲方可变更程度 $d$ 是关于项目投入资金量 $v$ 和项目进度 $t$ 的函 数, 且随着资金量和时间的增加函数递减, 即 甲方可变更程度表示为:

$$
d=f(\mathrm{v}, \mathrm{t})
$$

随着工程的推进，随着投入资金量和项目 进度的增加, 甲方可变更程度函数递减, 项目
的可变更程度越来越小, 由甲方变更带来的项 目风险及损失递增, 其函数图像如图 1 所示。

EPC 项目一般签订固定总价合同, 除非业 主主动提出, 合同价格保持不变, 但并非所有 由于甲方造成的变更均可向业主索赔, 业主只 承担初步设计之外的变更费用。甲方需求变更 会导致项目原计划被打乱, 从而引发合同风 险, 总承包商需根据要求制定变更计划, 重新 进行项目概算, 使得项目成本增加、工期延长、 管理难度加大。

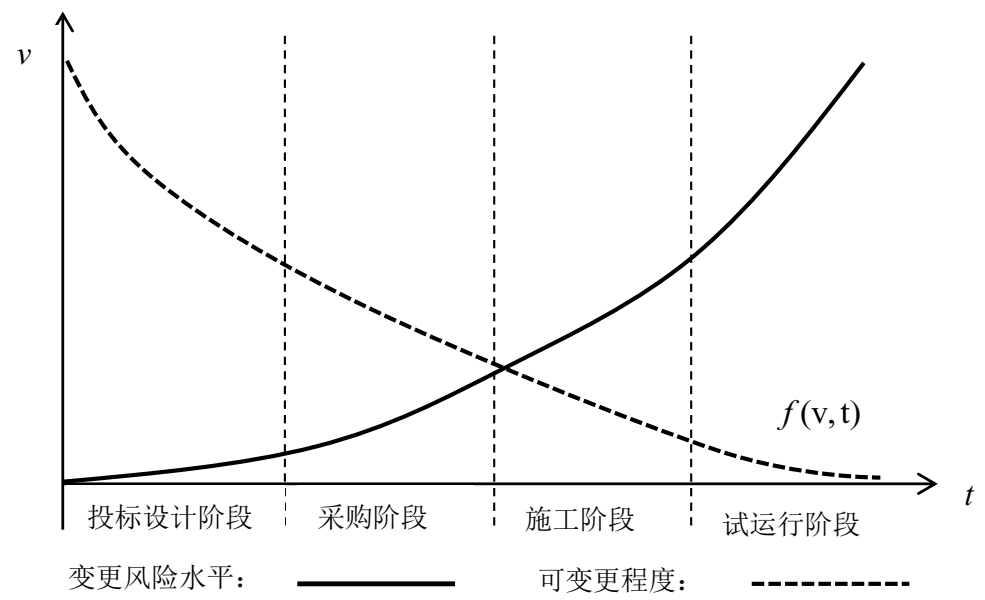

图 $1 \mathrm{EPC}$ 项目甲方可变更程度函数图

\section{4 交验风险}

EPC 项目的最终目的是满足业主方在合 同中要求的性能参数, 达到技术性能要求并投 入使用, 因此项目竣工后的综合性调试工作是 EPC 项目试运行阶段的必要程序, 只有达到项 目各项运行指标, 项目才能顺利交验。项目试 运行是对项目整体设计、施工和管理工作的综 合性检验, 是项目投入使用的前提和基础, 需 按设计生产能力满负荷运行以考验工程质量, 此阶段总承包商的主要工作是按合同约定向 业主提供试运行的指导和服务, 面临的主要风 险包括设备调试运维风险和技术风险, 项目移 交后进入工程缺陷责任期 (保修期), 此期间 的部分风险也需由总承包商承担。

\section{EPC 模式下来自甲方风险的应对}

科学的决策是盈利的前提, 由于 EPC 项 目的复杂性和信息的不对称性, 在利益的驱动
下盲目投标必定会带来极大的风险。在项目的 建设过程中, 总承包商的管理水平决定了项目 的质量、成本和施工进度, 其风险管理水平也 决定了项目的盈利水平, 如何应对项目承建过 程中来自甲方的风险, 也成为项目风险管理的 关键。

风险分析是风险应对的基础, 采取合适的 风险分析方法是工程项目风险管理的关键 ${ }^{[7]}$ 。 甲方风险具有多样性、全局性、复杂性等特点, 总承包企业需在项目全寿命周期内形成全方 位的风险防范体系 ${ }^{[8]}$ 。针对项目各阶段来自甲 方风险的风险因素及风险来源, 制定不同侧重 点的风险应对措施, 可以利用有限资源更加有 效地防范风险、控制损失。不同项目阶段来自 甲方风险的防范措施如图 2 所示。 
Risk Analysis and Crisis Response in Big Data Era (RAC-16)

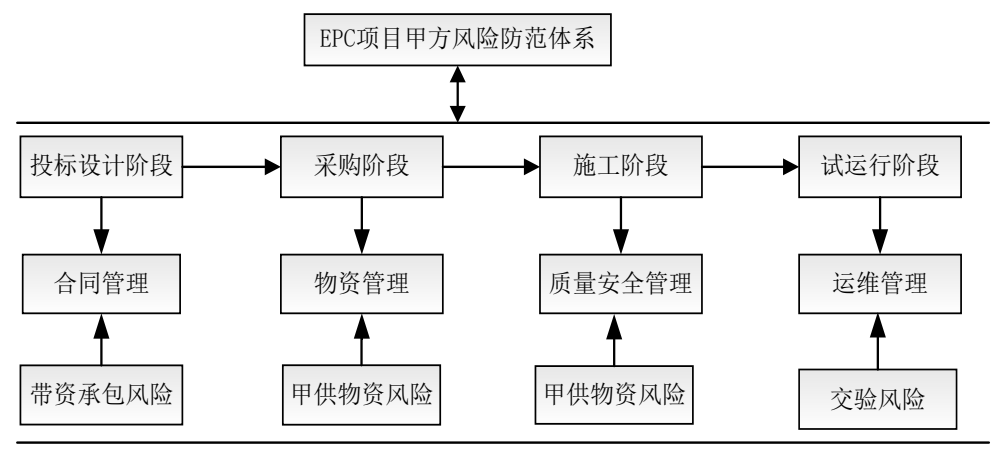

图 2 甲方风险应对图

\section{1 合同管理}

合同是双方履约的唯一依据，通常情况 下, $\mathrm{EPC}$ 项目是按照甲方需求、初步设计及项 目概算信息签订的固定总价合同，即在合同签 订时默认总承包商已预见了项目的一切困难 和费用, 合同总价不随项目环境和工程量的变 化而改变, 并对项目质量、工期、造价等全面 负责。但由于工期长、技术复杂、不确定性因 素多等原因, 在工程建设过程中不可避免会出 现工程变更导致一方违约的情况, 这对总承包 商的合同管理提出了较高要求。

$\mathrm{EPC}$ 工程项目合同管理贯穿于项目建设 的全过程, 加强合同管理是项目顺利推进的关 键。首先, 总承包商应在签订合同时根据业主 招标文件的具体要求, 准确、全面、清晰地拟 订合同条款, 明确合同执行规范、合同价款、 付款条件及方式等条款; 其次, 明确工作范围 及工期, 及时确定超出合同范围的变更, 依据 工程变更程序处理变更事项、应对变更风险; 再次, 加强合同索赔及反索赔管理, 发生纠纷 或违约事件时, 准确明确索赔内容, 及时搜集 证据提出索赔, 利用专业意见进行正确的索赔 决策 ${ }^{[9]}$ 。

\section{2 物资管理体系}

项目物资是工程质量和进度的关键, $\mathrm{EPC}$ 项目物资管理通常包括物资计划制定、采购、 运输、验收、存储、使用等环节, 是总承包项 目顺利实施的前提和基础。依据供应链及关键 链理论, 将供应链管理应用至 EPC 项目的物 资管理中, 以业务流程再造方式减少管理延 讯，构湕以愐日为核小、以物瓷管理为主要内
容、以信息共享为平台的高效物资管理体系 [10], 有利于提升项目资源使用效率、增强项目 管理的系统性, 降低造价、缩短工期、提高利 润, 实现项目价值最大化的管理目标。

项目建设施工过程中, 针对甲供物资的管 理主要集中在计划、验收入库、库存管理、使 用结算等方面。总承包商应根据设计方案制定 所需物资计划交由业主方采购, 施工材料到达 现场后注重物资数量、质量、规格的验收, 入 库后将物资运用帕累托 $\mathrm{ABC}$ 分类法对库存进 行分类管理。在项目部建立物资管理机构负责 物资供应和管理, 通过信息化提升物资管理水 平, 为项目施工建设效率提供保障。

\section{3 运维管理}

建筑信息模型（Building Information Construction, BIM）技术可将规划、设计、施 工、运营等各阶段数据累积于数据库中, 可在 项目内部形成高效信息流, 实现对项目施工质 量、成本、进度及安全的集成管理 ${ }^{[11]}$ 。BIM模 型的应用核心是信息管理, 在EPC项目运维中 的主要功能包括设备运行管理、安保系统管 理、应急维护管理等。

BIM模型在运维阶段的应用基于项目前 期各阶段的数据集成, 项目竣工交付后, 基于 计算机可处理的建筑数据表示和交换标准

(IFC标准), 将BIM模型与业主运维管理系统 集成对接, 可以实现项目故障设备的快速定位 和检修、异常情况的统计分析以及运维信息的 动态调整和更新, 较好地避免项目交付时产生 的问题和风险。 
Risk Analysis and Crisis Response in Big Data Era (RAC-16)

\section{4. 结语}

$\mathrm{EPC}$ 模式的广泛应用对总承包商的风险 管理能力提出了更高的要求, 在实务中, 项目 业主方也是风险源之一, 来自甲方风险也贯穿 于项目始终。本文在项目管理理论的基础上, 结合风险管理过程总结出 $\mathrm{EPC}$ 项目中来自甲 方的风险, 基于总承包商视角识别并分析项目 各阶段来自业主方的风险因素及其可能导致 的结果, 并在此基础上提出来自甲方风险的应 对措施, 为总承包商风险管理提供更加全面的 理论指导和实践参考。

\section{参考文献}

[1] 孟宪海, 赵启. EPC模式下业主和承包商 的风险分担与应对. 国际经济合作. 2004(12): 45-46.

[2] 陈勇强, 顾伟. 工程项目风险管理研究综 述. 科技进步与对策。2012，29(18): 157-160.

[3] Al-Bahar J F, Crandall K C. Systematic Risk Management Approach for Construction Projects. Journal of Construction Engineering and Management. 1990, 3(116): 533-546.

[4] Wang G, Hu W, Duffield C. Risk Mitigation in Managing a Mega Project - a
Case Study of Gomal Zam Dam Construction. Journal of Risk Analysis and Crisis Response. 2014, 4(1): 2-9.

[5] 卓四清, 冯永洲. 建筑工程垫资承包合法 性研究. 石家庄经济学院学报. 2015(05): 105-108.

[6] 武艺, 李承梅. 浅析建筑工程带资承包的 法律规. 重庆建筑大学学报. 2004, 26(4): 119-121.

[7] Baloi D. Risk Analysis Techniques in Construction Engineering Projects. Journal of Risk Analysis and Crisis Response. 2012, 2(2): 115-123.

[8] 高慧, 王宗军. EPC模式下总承包商风险 防范研究. 工程管理学报. 2016.

[9] 张水波, 汪辉辉, 何伯森. EPC总承包工 程项目的争端与索赔. 国际经济合作. 2006(02): 36-38.

[10] Yeo K T, Ning J H. Integrating supply chain and critical chain concepts in engineer-procure-construct (EPC) projects. International Journal of Project Management. 2002, 20(4): 253-262.

[11] Yang Z, Li W. The Research and Application of BIM Technology in Overseas EPC Project[C]. 2014. 